\title{
Patient experience within the adult congenital heart disease outreach network: a questionnaire-based study
}

Georgina Ooues ${ }^{1}$, Paul Clift ${ }^{1}$, Sarah Bowater ${ }^{1}$, Sayqa Arif ${ }^{1}$, Andrew Epstein², Neeraj Prasad², Dawn Adamson ${ }^{3}$, Mandy Cummings ${ }^{3}$, Charles Spencer ${ }^{4}$, Paul Woodmansey ${ }^{4}$, Jenny Borley ${ }^{4}$, Thomas Ingram ${ }^{5}$, Adrian Morley-Davies ${ }^{6}$, William Roberts', Najmi Qureshi ${ }^{7}$, Susan Hawkesford ${ }^{1}$, Nichola Pope ${ }^{1}$, James Anthony ${ }^{1}$, Thomas Gaffey ${ }^{1}$, Sara Thorne ${ }^{1}$, Lucy Hudsmith ${ }^{1 *}$ and On behalf of The West Midlands ACHD Network, UK

\begin{abstract}
Background: Specialist multi-disciplinary care improves outcomes of Adult Congenital Heart Disease (ACHD) patients. Following the NHS England Congenital Heart Disease standards review, the aim is to deliver high quality, patient-centred, care closer to patients' homes. Cardiac investigations performed on the same day of outpatient appointments reduce the non-attendance rates. This young cohort of patients, benefits from comprehensive multi-disciplinary management. We developed a Patient Questionnaire across our West Midlands ACHD network to measure patient experience.
\end{abstract}

Methods: Patient questionnaires were distributed to patients attending outpatient clinics in all 8 Outreach Centres and the Level 1 ACHD Centre (University Hospitals Birmingham).

Results: 71 males (55\%) and 59 females (45\%), median age range 25-34 years old (range between 16 and 75 years old), returned the questionnaires $(n=130)$.

Most patients travelled less than one hour to hospital $(93 \%, n=120)$ and less than 20 miles $(86 \%, n=99)$. The mean travel distance was $14 \pm 12.3$ miles (range 1 to 160 miles), with Level 1 ACHD Centre patients travelling a significantly longer distance (mean $29.6 \pm 44$ miles) compared to the local Outreach Centres (mean $11.3 \pm 9$ miles, $p=0.0037$ ). There was a wide variability in the provision of parking, although most patients found the appointment time and location convenient (91\%, $n=117$ and 95\%, $n=121$ respectively).

There was also marked variation in the number of electrocardiograms (19-100\%) and echocardiograms (0-60\%) performed on the same day as their clinic appointment.

Most patients felt they were given enough information regarding their condition $(85 \%, n=98)$, with no significant differences between the centres ( $p=0.24$ ).

Conclusion: To our knowledge, this is the first questionnaire-based study assessing patient experience within the NHS ACHD Outreach network with significantly reduced travel times and maintained high patient satisfaction. There was a wide variation in investigations performed and patient information leaflets provided. Standardisation of services is required at all centres to ensure equity of care, with Specialist Nurses' input and more availability of tests on the day of clinic appointments in all centres.

Keywords: Adult congenital heart disease, Patient questionnaire, Patient experience, Network services, Did not attend rates, Travel distance, Patient-centred care

\footnotetext{
*Correspondence: lucy.hudsmith@uhb.nhs.uk

'Department of Cardiology, Queen Elizabeth Hospital NHS Trust, Birmingham

B15 2TH, UK

Full list of author information is available at the end of the article
}

(c) The Author(s). 2018 Open Access This article is distributed under the terms of the Creative Commons Attribution 4.0 International License (http://creativecommons.org/licenses/by/4.0/), which permits unrestricted use, distribution, and reproduction in any medium, provided you give appropriate credit to the original author(s) and the source, provide a link to the Creative Commons license, and indicate if changes were made. The Creative Commons Public Domain Dedication waiver (http://creativecommons.org/publicdomain/zero/1.0/) applies to the data made available in this article, unless otherwise stated. 


\section{Background}

Congenital heart defects are the most common birth defects [1]. Current estimates suggest congenital heart disease (CHD) prevalence worldwide of 9 per 1000 live births (in Europe 8.2 in 1000 live births) [1], corresponding to 1.35 million babies born with some form of CHD each year. Current advances in surgical and interventional procedures have dramatically improved the outlook for CHD patients such that the majority (>95\%) are now expected to survive into adulthood [2, 3]. This has led to rapidly increasing new cohorts of adult survivors with CHD [4] and a significant increase in the number of patients with simple and complex adult congenital heart disease (ACHD) presenting to the Emergency Departments [5], admitted to hospital [6] or undergoing a pregnancy [7]. A large proportion of patients continue to require surgical and interventional procedures during adult life [8, 9], as well as arrhythmia management [10], advanced therapies and transplantation [11]. Most require lifelong advice and follow up by an ACHD Specialist.

Specialist care of patients with ACHD in multi-disciplinary tertiary care centres has been shown to improve outcomes and is recommended by international guidelines [12-15]. In the United Kingdom, The NHS England Congenital Heart Disease standards of care [16] were developed, which are based on the principle of a network model. These aim to deliver high quality, safe and effective services as locally as possible, with agreed pathways and protocols for referrals and follow up of these patients. The Network Care Levels include: Level 1: Specialist ACHD Surgical Centres, Level 2: Specialist ACHD Centres and Level 3: Local ACHD Centres.

In accordance with the NHS England CHD standards of care, our outreach network aims to deliver this in the West Midlands, United Kingdom. Improving available local cardiac expertise is vital, as local hospitals are often the first port of call for these patients when they become unwell. Patients with simple and complex ACHD are likely to present to local Emergency Departments with acute medical emergencies [17]. We have developed this service by providing network training days for the physicians and nursing staff involved in the care of the ACHD patients, as well as local professional training and support of specialist nurses, echocardiographers and nursing staff.

By providing local services closer to patients' homes, patient 'Do Not Attend' (DNA) rates to outpatient clinics are reduced, which is associated with better survival [18]. Previous work has shown patients are more likely to attend their outpatient appointment when they have an investigation, such as an echocardiogram or pacemaker interrogation, scheduled on the same day [18]. By coordinating services to involve multiple tests on the same day and improving communication to increase attendance, we hope, patient outcomes will be improved.

We developed a Patient Questionnaire across our ACHD network in West Midlands to measure patient experience and satisfaction across the network.

\section{Methods}

The West Midlands ACHD Network consists of the Level 1 ACHD Centre (University Hospital Birmingham) as the "hub" which provides all specialist ACHD services, including ACHD surgery and interventional cardiac catheterisation. The Level 1 Centre works in close collaboration with the rest of ACHD Centres, which are in the process of achieving level 2 and 3 status. Outreach outpatient clinics are run in the Local ACHD Centres with variable frequency depending on need (4-12 per year), in the presence of a Specialist Consultant from the Level 1 ACHD Centre.

Anonymous patient questionnaires (see Fig. 1) were distributed to patients reviewed in all eight (8) outpatient Outreach ACHD clinics and outpatient clinics at the Level 1 ACHD Centre in Birmingham.

The questions included information on demographics, travel to appointments, distance travelled and journey time, car parking and public transport and whether the location was convenient. They were also asked whether they were reviewed by an ACHD Specialist Nurse, which investigations were performed on the same day and if they were provided with information regarding their condition and appropriate patient information leaflets. Most questions were structured as a multiple-choice answer or a yes/no answer, in order to facilitate quick and easy to fill answers.

\section{Ethical statement}

The questionnaire was approved by our hospitals' patient experience service, in order to ensure the questions were clear, understandable, culturally sensitive and had taken into account any special needs of the patients. Patients were informed of the rationale and voluntary nature of the questionnaire and the anonymity of their responses.

\section{Statistical analysis}

For each question, descriptive statistics were used to determine the number of responses and proportions. Data was expressed either as mean with standard deviation or median with inter-quartile range. Categorical variables are presented as absolute numbers and percentages. Unpaired t-test was used for statistical analysis and probability values $<0.05$ were considered significant. All analyses were performed with the use of SPSS Statistics (version 25). 


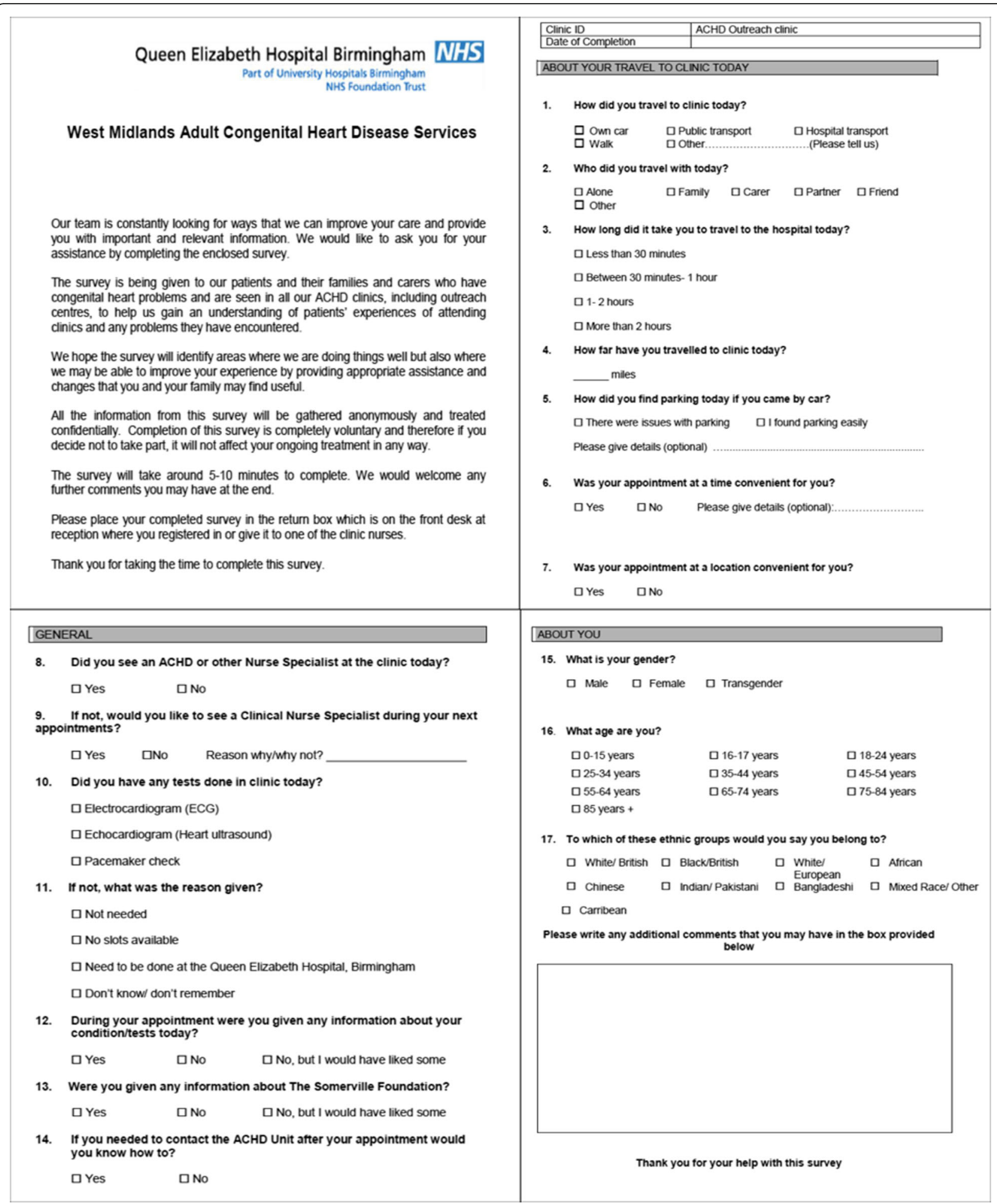

Fig. 1 Example of anonymised patient experience questionnaire which was distributed to patients in ACHD outpatient clinics 


\section{Results}

Patient questionnaires were distributed to all patients seen in all eight outreach outpatient clinics and outpatient clinics at the Level 1 ACHD Centre over a period of 5 months, between May and August 2017. One hundred thirty questionnaires were returned. Data were analysed only from the information filled by patients in the returned questionnaires.

Seventy-one males (55\%) and 59 females (45\%), with age range between 16 and 75 years old (median age range 25 to 34 years old) returned the questionnaires. The majority of patients were of White British ethnic group (92\%, $n=$ 117), followed by Indian or Pakistani group $(5 \%, n=6)$, with only two patients being of Black British $(1 \%, n=1)$ or European background $(1 \%, \mathrm{n}=1)$ (Table 1$)$.

The majority of patients $(67 \%, n=87)$ travelled to their appointment with their own car, either alone $(36 \%, n=$ $46)$ or with a member of their family $(44 \%, n=56)$. Most patients travelled less than $1 \mathrm{~h}$ to hospital $(93 \%, n=120)$ and less than 20 miles $(86 \%, n=99)$. The average travel distance that patients had to travel to their appointment was $14 \pm 12.3$ miles (median 10 miles, range 1 to 160 miles). Patients attending Level 1 ACHD Centre appointments travelled a significantly longer distance (mean 29.6 \pm 44 miles, median 13 miles, range 1 to 160 miles) compared to the Outreach Centres (mean $11.3 \pm 9$ miles, median 8.3 miles, range 0.5 to 50 miles) (95\% CI 6.1 to $30.4, p=0.0037$ ) (Table 2).

$26 \%(n=7)$ of patients who attended the Level 1 Centre used public transport, in comparison to only $6 \%$ (total $\mathrm{n}=8$ ) of patients attending the other centres. Patients experienced issues with parking in all centres: mainly long queues or inadequate parking spaces. Almost all patients found the appointment time and location convenient (91\%, $n=117$ and 95\%, $n=121$, respectively).

Electrocardiograms (ECGs) were performed in 71\% ( $n$ =92) of patients attending any ACHD Centre but there was large variation between centres (19-100\%). Only a small number of patients had an echocardiogram on the same day as clinic (0-60\%) and only one pacemaker interrogation was performed on the same day in the sampled population. $88 \%(n=21)$ of patients who attended clinics at the level 1 ACHD Centre (University Hospital Birmingham) had an ECG performed on the day compared to $73 \%(n=71)$ in the Outreach Centres $(p=0.21)$, and $25 \%(n=6)$ of patients had an echocardiogram performed at the level 1 ACHD Centre, compared to $21 \%$ $(n=23)$ in the Outreach Centres $(p=0.63)$.

The majority of patients felt they were given sufficient information about their condition $(85 \%, n=98)$, with no significant differences between the centres $(p=0.24)$. However, only $19 \%(n=22)$ reported being provided with patient information leaflets and only $69 \%(n=80)$ reported knowing how to contact the ACHD team, despite contact information cards being available in all locations. There was no statistically significant difference between the Level 1 and the local centres $(p=0.21)$.

There were differences in perceived review by an ACHD Specialist Nurse during their appointment (21$80 \%$ ), with potential confusion between outpatient clinic nurses and ACHD specialist Nurses, highlighting the need for wider availability and also further education on the role and expertise of Specialist ACHD nurses.

\section{Discussion}

The NHS England CHD standards [16] specify that ACHD networks should work to improve life expectancy and quality of life for adults with CHD, via 'the development of Congenital Heart Networks. Each ACHD network should deliver a standardised model of care which meets national service standards, 'systematically measuring and acting upon patient experience and satisfaction and contributing to patient surveys where they exist'. Our aim was to measure patient experience across our network and ensure high standards of care are maintained as well as further developing and improving this service.

Questionnaires are commonly used in everyday clinical practice, both in primary $[19,20]$ and secondary care $[21,22]$, e.g. in the assessment of cancer services [23, 24]. It has been widely recognised that patients' perspectives on their care and experience are essential in achieving high quality care [25]. Direct feedback from patients is considered the best way to measure the quality of their experiences [26]. In Cardiology there has been a growing emphasis in quality measures aimed at improving quality of care $[27,28]$. Although there are increasing attempts to standardise metrics of care and outcomes in congenital heart disease $[29,30]$, there are scarce data on the ACHD population.

Our cohort consists of relatively young patients who are largely working and/or looking after young families [31]. Thus, providing high quality services local to patients' workplace and domestic life is important in optimising patient compliance, minimising DNA rates and improving long-term follow up and engagement in healthcare [32]. By delivering services and outpatient appointments locally, we found that the average distance to hospital and travelling times are significantly reduced. The median travel distance to attend an outpatient clinic at all centres was 10 miles and to attend a level 1 ACHD centre was 13 miles (see Table 2). This is lower than contemporary published data from another UK centre, by Kempny et al. who reported a median travel distance of 26.8 miles [18]. Patients attending Level 1 ACHD Centre appointments travelled a significantly longer distance (mean 29.6 \pm 44 miles) compared to the Outreach Centres (mean 11.3 \pm 9 miles), reflecting local geography 


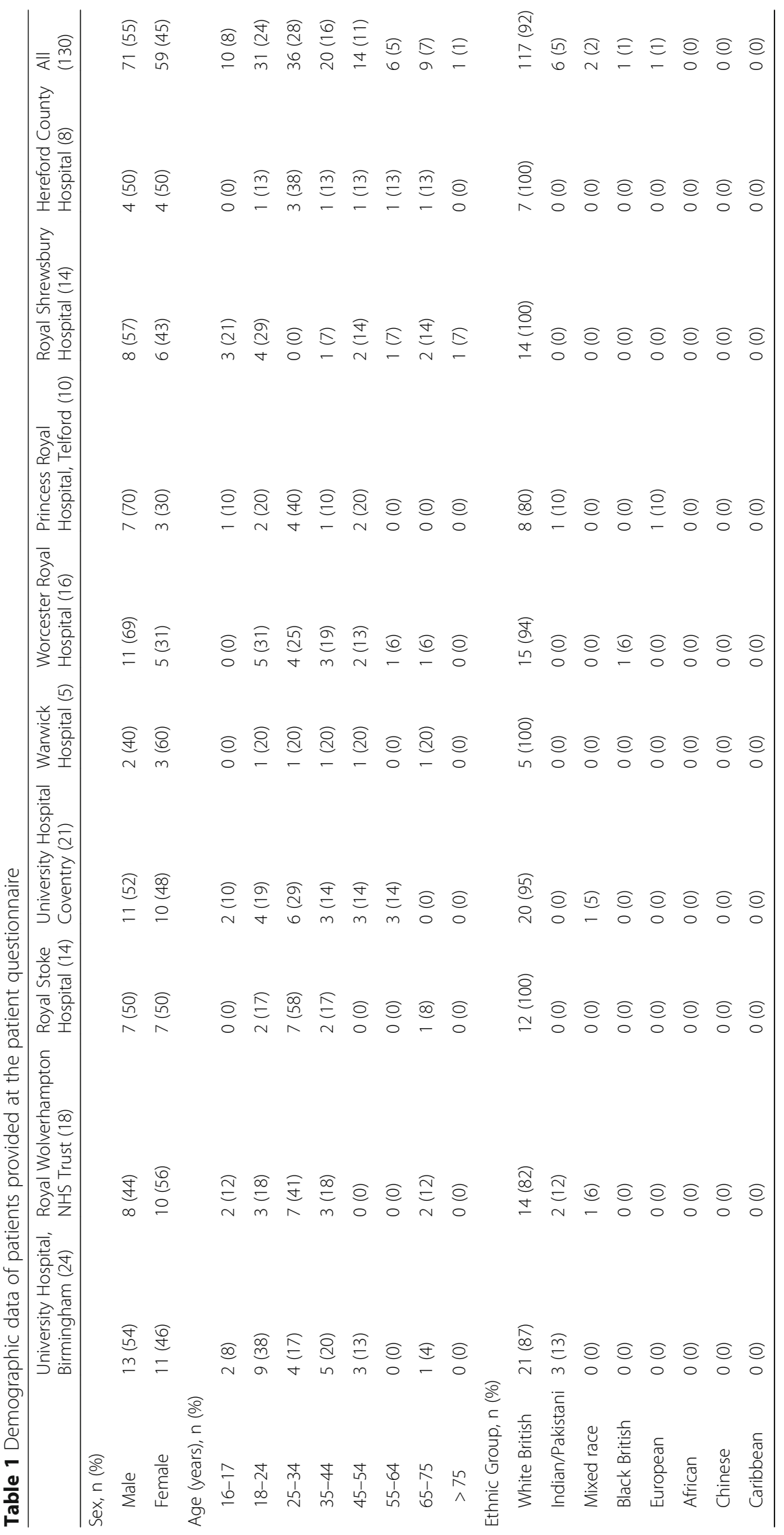


Table 2 Mean travel in miles of patients attending the outpatient clinics

\begin{tabular}{|c|c|c|c|c|}
\hline & Travel (miles) & & & \\
\hline & Mean & Median & Range & SD \\
\hline University Hospital Birmingham & 29.6 & 13 & $(2-160)$ & 44.0 \\
\hline Royal Wolverhampton NHS Trust & 6.0 & 3 & $(1-20)$ & 5.9 \\
\hline Royal Stoke Hospital & 12.5 & 12 & $(2-30)$ & 8.8 \\
\hline University Hospital Coventry & 12.6 & 9.5 & $(2-50)$ & 11.2 \\
\hline Warwick Hospital & 5.8 & 5.5 & $(2-10)$ & 3.5 \\
\hline Worcester Royal Hospital & 11.3 & 9 & $(1-25)$ & 8.0 \\
\hline Princess Royal Hospital, Telford & 8.9 & 10 & $(2-20)$ & 6.3 \\
\hline Royal Shrewsbury Hospital & 12.2 & 12 & $(2-20)$ & 8.8 \\
\hline Hereford County Hospital & 9.8 & 5.5 & $(0.5-30)$ & 10.5 \\
\hline \multirow[t]{2}{*}{ All } & 14.0 & 10 & $(0.5-160)$ & 12.3 \\
\hline & Mean travel & Median travel & Range & SD \\
\hline University Hospital Birmingham & 29.6 & 13 & $(2-160)$ & 44.04 \\
\hline All other hospitals & 11.3 & 8.5 & $(0.5-50)$ & 9.03 \\
\hline
\end{tabular}

(SD standard deviation)

of the West Midlands network but is of similar distance to Kempny et al. [18] who report another two ACHD Centres in their immediate catchment area.

A number of patients had additional tests performed the same day of their clinic appointment, such as ECG and echocardiograms, to enable appropriate comprehensive review of the patients, but also hopefully to improve attendance rates [18]. However, there was a large variation in the number of investigations performed, with ECG performed in only 19\% of patients in one centre and no echocardiograms in another. To optimise patient care, it is important that all the centres provide all high quality services, with echocardiographers holding or working towards European Association of Cardiovascular Imaging (EACVI) CHD transthoracic echocardiography accreditation and highly trained cardiac physiologists to perform pacemaker, intracardiac defibrillator and implantable loop recorder device interrogations, with ongoing support from the Level 1 Centre.

Although a high proportion of patients (85\%) reported that they were given enough information about their condition, only $19 \%$ reported being provided with a patient information leaflet (Somerville Foundation leaflets) and only $69 \%$ recalled how to contact the ACHD team, highlighting the need for ongoing Specialist ACHD nurse input in all centres. ACHD Specialist nurses hold a key role within the multi-disciplinary ACHD team and form a crucial part of the care provided to these patients, as set out in the CHD standards [33-35].

As the population of adults with congenital heart disease increases, there has been an increase in emergency department attendances and hospital admissions [5]. These patients are also likely to undergo pregnancies and thus benefit from local care with specialist obstetric and midwifery input and in some cases delivery closer to home. In other cases, patients may need close monitoring of their blood tests, including international normalised ratio (INR) test in an anticoagulation clinic or require palliative care services and thus should have access to local resources.

A network model of services in different hospitals and areas local to these patients, allowing patient access to services closer to home, benefits both patients and also the local framework of healthcare workers. By increasing the exposure of local teams to patients with complex ACHD diseases, they are more equipped in managing these patients when they present to their local Emergency Department. They also start to gain patients' and their families' confidence in providing them with high quality treatment in their local hospitals.

Our aim across our ACHD network is to develop a consistent, coherent system and availability of services, in order to provide a standardised model of care in all outreach centres, as defined by the NHS England CHD standards [16]. With the ongoing training of CHD-trained echocardiographers and specialist pacing physiologists, we aim to reduce the variation between centres on investigations performed at the same day of patients' outpatient clinic appointment and provide similar high quality services across all centres. In order to provide resilient 24/7 care, we aim to develop the training of local Cardiologists, Obstetricians, Emergency Department doctors and nursing staff via our Network meetings, Specialist Registrar and Nursing training days and weekly multi-disciplinary meetings, to ensure our patients' care consistently meets the standards of care throughout the West Midlands. 


\section{Limitations}

The number of questionnaires collected is small (approximately $2 \%$ of our ACHD patients) which may limit some of the conclusions. The majority of patients were white British ethnic group which limits the ethnic diversity of our study population. In addition, we have not collected any data on socioeconomic status, disease severity or DNA rates and further studies are warranted to assess these.

\section{Conclusions}

To the best of our knowledge, this is the first survey-based study assessing patient experience within the NHSE ACHD Outreach network.

Our findings show that the development of ACHD Network Outreach clinics to facilitate services and appointments closer to patients' homes, travel times are significantly reduced and high patient satisfaction is preserved. There is variation in patient care, including investigations performed on the clinic day, patient information leaflets and specialist nurse input. Standardisation of protocols for the "spoke" centres is recommended to ensure equity for all patients. Availability of investigations on the same day as clinic should be improved throughout the network.

\section{Abbreviations}

ACHD: Adult congenital heart disease; CHD: Congenital heart disease; DNA: Do Not Attend; EACVI: European Association of Cardiovascular Imaging: ECG: Electrocardiogram; INR: International normalised ratio; NHS: National Health Service; SD: Standard deviation

\section{Availability of data and materials}

The patient questionnaires and data generated and/or analysed during the current study are available from the corresponding author on reasonable request.

\section{Authors' contributions}

GO and LH conceived the idea. GO collected the data. GO and LH analysed the data. The initial draft of the article was written by GO and LH, PC, ST, SB and $\mathrm{SA}$ assessed and edited the manuscript. All authors read and approved the final manuscript.

\section{Ethics approval and consent to participate}

As this questionnaire evaluated a clinical service and there was no deviation from normal clinical practice, formal NHS Research Ethics Committee was not required. Patients were informed of the rationale and voluntary nature of the questionnaire and the anonymity of their responses. Informed consent was implied by the return of the questionnaire.

\section{Consent for publication}

Not applicable.

\section{Competing interests}

The authors declare that they have no competing interests.

\section{Publisher's Note}

Springer Nature remains neutral with regard to jurisdictional claims in published maps and institutional affiliations.

\section{Author details}

'Department of Cardiology, Queen Elizabeth Hospital NHS Trust, Birmingham B15 2TH, UK. ${ }^{2}$ Hereford County Hospital, Hereford HR1 2BN, UK. ${ }^{3}$ University
Hospital Coventry, Coventry CV2 2DX, UK. ${ }^{4}$ Royal Wolverhampton NHS Trust, Wolverhampton WV10 0QP, UK. 'Shrewsbury and Telford Hospital NHS Trust, Shrewsbury SY3 8XQ, UK. ${ }^{6}$ Royal Stoke University Hospital, Stoke-on-Trent ST4 6QG, UK. ${ }^{7}$ Worcester Royal Hospital, Worcester WR5 1DD, UK. ${ }^{8}$ Warwick Hospital, Warwick CV34 5BW, UK

Received: 7 May 2018 Accepted: 2 August 2018

Published online: 03 September 2018

\section{References}

1. van der Linde D, Konings EEM, Slager MA, Witsenburg M, Helbing WA, Takkenberg JJM, et al. Birth prevalence of congenital heart disease worldwide. J Am Coll Cardiol. 2011:58:2241-7.

2. Le Gloan L, Mercier L-A, Dore A, Marcotte F, Ibrahim R, Mongeon F-P, et al. Recent advances in adult congenital heart disease. Circ J. 2011;75:2287-95.

3. Diller G-P, Kempny A, Alonso-Gonzalez R, Swan L, Uebing A, Li W, et al. Survival prospects and circumstances of death in contemporary adult congenital heart disease patients under follow-up at a large tertiary Centre. Circulation. 2015;132:2118-25.

4. Marelli AJ, lonescu-Ittu R, Mackie AS, Guo L, Dendukuri N, Kaouache M. Lifetime prevalence of congenital heart disease in the general population from 2000 to 2010. Circulation. 2014:130:749-56.

5. Agarwal S, Sud K, Khera S, Kolte D, Fonarow GC, Panza JA, et al. Trends in the burden of adult congenital heart disease in US emergency departments. Clin Cardiol. 2016;39:391-8.

6. Verheugt CL, Uiterwaal CSPM, van der Velde ET, Meijboom FJ, Pieper PG, Sieswerda GT, et al. The emerging burden of hospital admissions of adults with congenital heart disease. Heart. 2010;96:872-8.

7. Cauldwell M, Steer PJ, Bonner S, Asghar O, Swan L, Hodson K, Head CEG, Jakes AD, Walker N, Simpson M, Bolger AP, Siddiqui F, English KM, Maudlin L, Abraham D, Sands AJ, Mohan AR, Curtis SL, Coats L, Johnson MR. Retrospective UK multicentre study of the pregnancy outcomes of women with a Fontan repair. Heart. 2018;104(5):401-6. https://doi.org/10.1136/heartjnl-2017-311763. Epub 2017 Sep 27

8. Bhagra CI, Hickey EJ, Van De Bruaene A, Roche SL, Horlick EM, Wald RM. Pulmonary valve procedures late after repair of tetralogy of Fallot: current perspectives and contemporary approaches to management. Can J Cardiol. 2017;33:1138-49.

9. Frankfurter C, Asgar AW, Webb JG, Cantor WJ, Velianou JL, Gobeil F, et al. Adult congenital heart disease intervention: the Canadian landscape. Can J Cardiol. 2017:33:1201-5.

10. Khairy P, Van Hare GF, Balaji S, Berul Cl, Cecchin F, Cohen Ml, et al. PACES/ HRS expert consensus statement on the recognition and Management of Arrhythmias in adult congenital heart disease. Can J Cardiol. 2014;30:e1-63. https://doi.org/10.1016/j.cjca.2014.09.002.

11. Matsuda $H$, Ichikawa $H$, Ueno $T$, Sawa $Y$. Heart transplantation for adults with congenital heart disease: current status and future prospects. Gen Thorac Cardiovasc Surg. 2017:65:309-20.

12. Mylotte D, Pilote L, lonescu-Ittu R, Abrahamowicz M, Khairy P, Therrien J, et al. Specialized adult congenital heart disease care: the impact of policy on mortality. Circulation. 2014;129:1804-12.

13. Silversides CK, Marelli A, Beauchesne L, Dore A, Kiess M, Salehian O, et al. Canadian cardiovascular society 2009 consensus conference on the management of adults with congenital heart disease: executive summary. Can J Cardiol. 2010:26:143-50.

14. Warnes CA, Williams RG, Bashore TM, Child JS, Connolly HM, Dearani JA et al. ACC/AHA 2008 guidelines for the Management of Adults with Congenital Heart Disease. J Am Coll Cardiol. 2008;52:e143-263.

15. Baumgartner H, Bonhoeffer P, De Groot NMS, de Haan F, Deanfield JE, Galie $\mathrm{N}$, et al. ESC guidelines for the management of grown-up congenital heart disease (new version 2010). Eur Heart J. 2010;31:2915-57.

16. NHS England N. Adult congenital heart disease (ACHD) specification. NHS England; 2016. https://www.england.nhs.uk/wp.../Congenital-heart-diseasespecification-adults.pdf.

17. Kaemmerer H, Fratz S, Bauer U, Oechslin E, Brodherr-Heberlein S, Zrenner B, et al. Emergency hospital admissions and three-year survival of adults with and without cardiovascular surgery for congenital cardiac disease. J Thorac Cardiovasc Surg. 2003;126:1048-52.

18. Kempny A, Diller G-P, Dimopoulos K, Alonso-Gonzalez R, Uebing A, Li W, et al. Determinants of outpatient clinic attendance amongst adults with congenital heart disease and outcome. Int J Cardiol. 2016;203:245-50. 
19. Roberts MJ, Campbell JL, Abel GA, Davey AF, Elmore NL, Maramba I, et al. Understanding high and low patient experience scores in primary care: analysis of patients' survey data for general practices and individual doctors. BMJ. 2014;349:96034.

20. Boiko O, Campbell JL, Elmore N, Davey AF, Roland M, Burt J. The role of patient experience surveys in quality assurance and improvement: a focus group study in English general practice. Health Expect. 2015;18:1982-94.

21. Wong ELY, Coulter A, Hewitson P, Cheung AWL, Yam CHK, Lui SF, et al. Patient experience and satisfaction with inpatient service: development of short form survey instrument measuring the core aspect of inpatient experience. PLoS One. 2015;10:e0122299. https://doi.org/10.1371/journal. pone.0122299.

22. Jornet AR, Castellanos LAB, Contador MIB, Morera JCO, López JAI. Usefulness of questionnaires on advance directives in haemodialysis units. Nephrol Dial Transplant. 2017;32:1676-82.

23. Tsianakas V, Maben J, Wiseman T, Robert G, Richardson A, Madden P, et al. Using patients' experiences to identify priorities for quality improvement in breast cancer care: patient narratives, surveys or both? BMC Health Serv Res. 2012;12:271.

24. Horevoorts NJ, Vissers PA, Mols F, Thong MS, van de Poll-Franse LV. Response rates for patient-reported outcomes using web-based versus paper questionnaires: comparison of two invitational methods in older colorectal cancer patients. J Med Internet Res. 2015;17:e111.

25. Doyle C, Lennox L, Bell D. A systematic review of evidence on the links between patient experience and clinical safety and effectiveness. BMJ Open. 2013;3:e001570.

26. Rathert C, Brandt J, Williams ES. Putting the "patient" in patient safety: a qualitative study of consumer experiences. Health Expect. 2012;15:327-36.

27. Brush JE, Rensing E, Song F, Cook S, Lynch J, Thacker L, et al. A statewide collaborative initiative to improve the quality of care for patients with acute myocardial infarction and heart failure. Circulation. 2009;119:1609-15. https://doi.org/10.1161/CIRCULATIONAHA.108.764613.

28. Heidenreich PA, Solis P, Estes NAM, Fonarow GC, Jurgens CY, Marine JE, et al. 2016 ACC/AHA clinical performance and quality measures for adults with atrial fibrillation or atrial flutter. J Am Coll Cardiol. 2016;68:525-68.

29. Welke KF, Jacobs JP, Jenkins KJ. Evaluation of quality of care for congenital heart disease. Semin Thorac Cardiovasc Surg Pediatr Card Surg Annu. 2005; 8:157-67.

30. Jacobs JP, Benavidez OJ, Bacha EA, Walters HL, Jacobs ML. The nomenclature of safety and quality of care for patients with congenital cardiac disease: a report of the society of thoracic surgeons congenital database taskforce subcommittee on patient safety. Cardiol Young. 2008; 18(Suppl 2):81-91.

31. Pickup L, Gaffey T, Clift P, Bowater S, Thorne S, Hudsmith L. Employment characteristics of a complex adult congenital heart disease cohort. Occup Med (Chic III). 2017:67:453-5.

32. Andrews R, Morgan JD, Addy DP, McNeish AS. Understanding nonattendance in outpatient paediatric clinics. Arch Dis Child. 1990;65:192-5.

33. Moons P, Scholte op Reimer W, De Geest S, Fridlund B, Heikkila J, Jaarsma T, et al. Nurse specialists in adult congenital heart disease: the current status in Europe. Eur J Cardiovasc Nurs. 2006;5:60-7.

34. Hatchett R, McLaren S, Corrigan P, Filer L. An evaluation of a specialist nursing service for adult patients with congenital heart disease. Int J Nurs Pract. 2015;21:556-65.

35. Moons P, De Geest S, Budts W. Comprehensive care for adults with congenital heart disease: expanding roles for nurses. Eur J Cardiovasc Nurs. 2002;1:23-8.

Ready to submit your research? Choose BMC and benefit from:

- fast, convenient online submission

- thorough peer review by experienced researchers in your field

- rapid publication on acceptance

- support for research data, including large and complex data types

- gold Open Access which fosters wider collaboration and increased citations

- maximum visibility for your research: over $100 \mathrm{M}$ website views per year

At BMC, research is always in progress.

Learn more biomedcentral.com/submissions 